ACCEPTED MANUSCRIPT

\title{
Breath-based non-invasive diagnosis of Alzheimer's disease: A pilot study
}

To cite this article before publication: Akira Tiele et al $2019 \mathrm{~J}$. Breath Res. in press https://doi.org/10.1088/1752-7163/ab6016

\section{Manuscript version: Accepted Manuscript}

Accepted Manuscript is "the version of the article accepted for publication including all changes made as a result of the peer review process, and which may also include the addition to the article by IOP Publishing of a header, an article ID, a cover sheet and/or an 'Accepted Manuscript' watermark, but excluding any other editing, typesetting or other changes made by IOP Publishing and/or its licensors"

This Accepted Manuscript is @ 2019 IOP Publishing Ltd.

During the embargo period (the 12 month period from the publication of the Version of Record of this article), the Accepted Manuscript is fully protected by copyright and cannot be reused or reposted elsewhere.

As the Version of Record of this article is going to be / has been published on a subscription basis, this Accepted Manuscript is available for reuse under a CC BY-NC-ND 3.0 licence after the 12 month embargo period.

After the embargo period, everyone is permitted to use copy and redistribute this article for non-commercial purposes only, provided that they adhere to all the terms of the licence https://creativecommons.org/licences/by-nc-nd/3.0

Although reasonable endeavours have been taken to obtain all necessary permissions from third parties to include their copyrighted content within this article, their full citation and copyright line may not be present in this Accepted Manuscript version. Before using any content from this article, please refer to the Version of Record on IOPscience once published for full citation and copyright details, as permissions will likely be required. All third party content is fully copyright protected, unless specifically stated otherwise in the figure caption in the Version of Record.

View the article online for updates and enhancements. 
Original Article

\section{Breath-based non-invasive diagnosis of Alzheimer's}

\section{disease: A pilot study}

Akira Tiele $^{1, \star}$, Alfian Wicaksono ${ }^{1}$, Emma Daulton ${ }^{1}$, Emmanuel Ifeachor ${ }^{2}$, Victoria Eyre ${ }^{3}$, Sophie Clarke ${ }^{3}$, Leanne Timings ${ }^{3}$, Stephen Pearson ${ }^{3}$, James A. Covington ${ }^{1, *}$ and Xinzhong $\mathrm{Li}^{4,5, *}$

1 School of Engineering, University of Warwick, Coventry CV4 7AL, UK

2 School of Computing, Electronics and Mathematics, University of Plymouth PL4 8AA, UK

${ }^{3}$ Re:Cognition Health, 5 Research Way, Plymouth PL6 8BT, UK

${ }^{4}$ Faculty of Medicine and Dentistry, University of Plymouth PL6 8BU, UK

${ }^{5}$ School of Science, Engineering and Design, Teesside University, TS1, 3BX, UK

* Corresponding authors:

F-A.Tiele@warwick.ac.uk;

J.A.Covington@warwick.ac.uk;

andX.Li@tees.ac.uk 
Abstract

Early detection of Alzheimer's disease (AD) will help researchers to better understand the disease and develop improved treatments. Recent developments have thus focused on identifying biomarkers for mild cognitive impairment due to $A D(\mathrm{MCl})$ and $A D$ during the preclinical phase. The aim of this pilot study is to determine whether exhaled volatile organic compounds (VOCs) can be used as a non-invasive method to distinguish controls from $\mathrm{MCl}$, controls from $\mathrm{AD}$ and to determine whether there are differences between $\mathrm{MCl}$ and $\mathrm{AD}$. The study used gas chromatography - ion mobility spectrometry (GC-IMS) techniques. Confounding factors, such as age, smoking habits, gender and alcohol consumption are investigated to demonstrate the efficacy of results. One hundred subjects were recruited including 50 controls, $25 \mathrm{AD}$ and $25 \mathrm{MCl}$ patients. The subject cohort was age- and gender-matched to minimise bias. Breath samples were analysed using a commercial GC-IMS instrument (G.A.S. BreathSpec, Dortmund, Germany). Data analysis indicates that the GC-IMS signal was consistently able to separate between diagnostic groups [AUC $\pm 95 \%$, sensitivity, specificity], controls vs MCI: [0.77 (0.64 - 0.90), 0.68, 0.80], controls vs AD: $[0.83(0.72-0.94), 0.60,0.96]$, and $\mathrm{MCl}$ vs $\mathrm{AD}:[0.70(0.55-0.85), 0.60$, 0.84]. VOC analysis indicates that six compounds play a crucial role in distinguishing between diagnostic groups. Analysis of possible confounding factors indicate that gender, age, smoking habits and alcohol consumption have insignificant influence on breath content. This pilot study confirms the utility of exhaled breath analysis to distinguish between $A D, M C I$ and control 
subjects. Thus, GC-IMS offers great potential as a non-invasive, high-throughput, diagnostic technique for diagnosing and potentially monitoring $A D$ in a clinical setting.

Keywords: Alzheimer's disease; mild cognitive impairment due to Alzheimer's disease (MCI); breath analysis; GC-IMS; volatile/organic compounds (VOCs). 
Journal of Breath Research

Page $\mid 4$

\section{Introduction}

The increasing lifespan of the human population is inevitably leading to a growing prevalence of neurodegenerative diseases (NDDs). Alzheimer's disease $(A D)$ is a degenerative brain disorder and is the most common cause of dementia [1]. Dementia is characterised by a decline in memory, language, problem-solving, planning, reasoning, and other basic cognitive abilities, which has a direct impact on performing everyday activities [2]. The decline occurs because nerve cells (neurons), in parts of the brain involved in cognitive functions, have been damaged or destroyed [2]. While there is currently no cure or way to stop or slow disease progression, medication, support and care can help manage symptoms and improve quality of life. In 2017, the worldwide dementia prevalence was estimated at 50 million people [3], with a global societal cost of $\$ 1$ trillion [4] resulting from direct (medical and social care) and indirect (unpaid caregiving by families and friends) costs. The economic impact and costs have been estimated to be greater than that common chronic diseases, such as heart disease and cancer [5].

Progression of AD can be categorised into three phases: preclinical, mild cognitive impairment (MCI) and clinical phases [6]. The preclinical phase does not include noticeable clinical signs; however, there are gradual physiological changes at the cellular level associated with disease pathogenesis [7]. $\mathrm{MCl}$ is used in this research to describe Mild Cognitive Impairment due to Alzheimer's disease. This is a transitory phase in the progression of AD from a preclinical illness to symptomatic $A D$, which then progresses to a dementia where there is impairment in more than one domain of cognitive function and activities of daily living, such as getting dressed and doing household activities. In this 
Journal of Breath Research

Page $\mid 5$

study, we use the term Alzheimer's disease (AD) to describe this progression from $\mathrm{MCl}$ to more than one domain of cognitive function and then to dementia where activities of daily living are becoming impaired. The assessment of $\mathrm{MCl}$ remains clinical, taking a history, checking dementia screening bloods, a brain scan (either CT or MRI scan) and using neuropsychology testing (e.g. using MoCA, ACE-III and M-ACE sub-score) to come to a clinical diagnosis. In research centres, biomarkers such as cerebrospinal fluid (CSF) testing and amyloid PET scans are used to confirm a biomarker diagnosis for $\mathrm{MCl}$ due to AD using NIA-AA criteria $[8,9]$.

It is widely accepted that early detection of AD (ideally, in the preclinical phase) will be key to preventing, slowing and stopping the disease [2]. This is when disease modifying treatments will be most effective. Some research has suggested that the first AD-related brain changes may begin more than 20 years before clinical symptoms emerge [10]. Identifying biomarkers that can reliably identify AD-related developments at an early stage would have a high clinical value, as it could enable early preventative treatments. Blood-based biomarkers, such as amyloid- $\beta$ markers [11], could provide minimally-invasive methods. However exhaled breath has shown potential as a non-invasive diagnostic tool. This involves the analysis of exhaled volatile organic compounds (VOCs). There are an estimate of over 3,000 VOCs in human breath, which are a combination of by-products of normal metabolic activity and, in some cases, specific biomarkers associated with a disease [12-15].

Exhaled breath analysis has the potential to have a significant impact on enhancing the diagnosis and monitoring of $A D$, since the approach is non-invasive, relatively cost-effective and potentially straight-forward to 
Journal of Breath Research

Page $\mid 6$

implement [7]. A recent review paper by Subramaniam et al. [7] explored the emergence of breath testing as a non-invasive diagnostic modality for NDDs. Early work by Stüwe et al. [16,17] used breath tests to investigate hepatic mitochondrial dysfunction for Friedreich ataxia and Huntington's disease. These studies utilised isotope-selective nondispersive infrared spectrometry (IRIS) for evaluation of methyl ${ }^{13} \mathrm{C}$-methionine. In addition to this, there have been at least four breath-based studies investigating the efficacy of diagnosing AD. These studies used gas chromatography-mass spectrometry (GC-MS) $[18,19]$, Cyranose 320 electronic nose (eNose) [20], ion mobility spectroscopy (IMS) [20] and custom-built sensor systems $[18,19,21]$. Three out of four of these studies investigated AD, as well as Parkinson's disease (PD), against control subjects. To the best of our knowledge, this breath study is the first to investigate $\mathrm{MCI}, \mathrm{AD}$ and controls using a GC-IMS (gas chromatography-ion mobility spectrometer) technique.

The aim of this pilot study is to determine whether exhaled VOCs can be used to distinguish controls from $\mathrm{MCl}$, controls from $\mathrm{AD}$, and $\mathrm{MCl}$ from $\mathrm{AD}$ in breath. Confounding factors, such as age, smoking habits, gender and alcohol consumption are investigated to demonstrate the efficacy of results. 


\section{Materials and methods}

\subsection{Subjects}

A total of 100 subjects were recruited for this case-control study. Ethical approval was obtained from local research ethics committee (Ref No. 17/18-829, University of Plymouth, UK). $\mathrm{MCl}$ and AD patients were recruited by Re:Cognition Health (Plymouth, UK), along with their respective partners as control subjects. The control subjects were clinically defined as non-MCI and AD sufferers. The volunteers and patients received information sheets and were consented following a face-to-face interview by a medical doctor. The study cohort includes 50 patients $(25 \mathrm{MCl}, 25 \mathrm{AD})$ and 50 controls. $\mathrm{MCl}$ patients were recruited based on the investigator's assessment (Author S.P.), who reviewed their clinical history and confirmed that the subject demonstrated amnestic symptoms highly suggestive of $A D$. AD subjects were recruited based on M-ACE scores [22] below 23, a clinical assessment of the presence of amnestic problems, and another domain of cognitive problems, including patients with dementia who had functional impairment. Controls included subjects that had no-known history of neurological disorders (self-reported). The mean age of the $\mathrm{MCl}$ and $\mathrm{AD}$ group was 74.9 (standard deviation: 7.6), including 29 males and 21 females. An overview of the demographic data of $\mathrm{MCl}, \mathrm{AD}$ and control subjects is shown in Table 1. 
Journal of Breath Research

Page $\mid 8$

Table 1. Demographic data of controls subjects and $\mathrm{MCl}$ and $\mathrm{AD}$ patients.

\begin{tabular}{|c|c|c|c|}
\hline Parameter & $\mathrm{MCl}(\mathrm{n}=25)$ & $A D(n=25)$ & Controls $(n=50)$ \\
\hline Mean age (SD) & $72.2(7.3)$ & $77.5(7.2)$ & $71.2(7.3)$ \\
\hline Gender ratio $\mathrm{M}: \mathrm{F}$ & $15: 10$ & $14: 11$ & 17:33 \\
\hline Smoking habits & $\begin{array}{c}16 \text { ex-smokers } \\
9 \text { never smokers }\end{array}$ & $\begin{array}{c}10 \text { never smokers } \\
12 \text { ex-smokers } \\
3 \text { current smokers }\end{array}$ & $\begin{array}{c}22 \text { never smokers } \\
25 \text { ex-smokers } \\
3 \text { current smokers }\end{array}$ \\
\hline $\begin{array}{l}\text { Alcohol - mean } \\
\text { units/week (SD) }\end{array}$ & $10.8(11.6)$ & $3.5(6.4)$ & $11.3(13.4)$ \\
\hline $\begin{array}{c}\text { Medication } \\
\text { (No. of Subjects) }\end{array}$ & $\begin{array}{c}\text { Omeprazole (8) } \\
\text { Atorvastatin (6) } \\
\text { Bisoprolol (5) } \\
\text { Paracetamol (4) } \\
\text { Simvastatin (4) } \\
\text { Amlodipine (3) } \\
\text { Warfarin (3) } \\
\text { Aspirin (3) } \\
\text { Citalopram (3) } \\
64 \text { others }(\leq 2) \\
\end{array}$ & $\begin{array}{l}\text { Donepezil (10) } \\
\text { Atorvastatin (6) } \\
\text { Omeprazole (4) } \\
\text { Aspirin (4) } \\
\text { Amlodipine (4) } \\
\text { Folic Acid (4) } \\
\text { Clopidogrel (3) } \\
\text { Citalopram (3) } \\
47 \text { others }(\leq 2)\end{array}$ & Not available (N/A) \\
\hline $\begin{array}{c}\text { Co-diseases / } \\
\text { conditions } \\
\text { (No. of Subjects) }\end{array}$ & $\begin{array}{c}\text { Hypertension (11) } \\
\text { Depression (6) } \\
\text { High Cholesterol (6) } \\
\text { Atrial Fibrillation (4) } \\
\text { Hiatus Hernia (3) } \\
\text { Migraines (3) } \\
\text { Diabetes Mellitus (3) } \\
58 \text { others }(\leq 2)\end{array}$ & $\begin{array}{l}\text { Hypertension }(7) \\
\text { High Cholesterol }(5) \\
\text { Gastric Reflux }(4) \\
54 \text { others }(\leq 2)\end{array}$ & Not available (N/A) \\
\hline
\end{tabular}

\subsection{Breath analysis platform}

This study utilised GC-IMS technology as an analytical platform. In recent years, there has been a growing presence of portable GC-IMS analysers, which have demonstrated capabilities in medical diagnostics [23,24]. The

BreathSpec (G.A.S., Dortmund, Germany) used in this study, is a commercial instrument, consisting of a gas chromatograph (GC) and an ion mobility 
spectrometer (IMS). Importantly, the unit analyses at point of care, only takes a few minutes to undertake an analysis and is patient friendly, with breath samples collected without putting strain on the subject. The BreathSpec is equipped with a MXT-200 mid-polarity column (Thames Restek, Saunderton, UK) for gas chromatographic separation, based on chemical interactions with the column. This stage is followed by a drift tube IMS detector, whereby analytes are ionised and injected into a drift tube, using a shutter grid. The ions drift against a buffer gas under influence of a uniform electric field $(400 \mathrm{~V} / \mathrm{cm})$, where the various ions achieve different velocities, inversely related to their size, mass and charge [25]. The ions are then collected on a Faraday plate, to produce a time-dependent signal that corresponds with ion mobility. This technique can measure substances in the low parts-per-billion (ppb) range and delivers measurement results in 10 minutes. This unit is fitted with a circulator gas flow unit (CGFU), which recirculates and filters ambient air. This allows the unit to operate without the need of an external gas supply (e.g. nitrogen generator). The buffer, gas flow rate was $150 \mathrm{ml} / \mathrm{min}$ and carrier flow rate through the instrument was $15 \mathrm{ml} / \mathrm{min}$, while the sample was being introduced. The carrier flow rate was then ramped to $50 \mathrm{ml} / \mathrm{min}$ over the 10-minute measurement time. The temperatures of the GC column, IMS and sample loop were set to $45^{\circ} \mathrm{C}$.

\subsection{Breath sampling}

The sampling procedure requires only four seconds of exhaled breath [26]. Subjects were provided with a disposable plastic mouthpiece, which pushes into the mouthpiece holder/sample inlet and connects directly to the 
Journal of Breath Research

Page $\mid 10$

front-panel of the instrument. The mouthpieces are open-ended, which allows air inside the mouthpiece to be displaced as exhalation proceeds. As a result, the sampling system can separate out the last portion of exhaled breath known as end-tidal breath. This refers to the last portion $(350 \mathrm{~mL})$ of exhaled breath, expelled from within the lungs and the lower-airways, which have undergone gaseous exchange with the blood in the alveoli [27]. Users do not need to exhale until their lungs are as empty as possible and instead are simply asked to breathe normally. This improves reproducibility and makes the device suitable for vulnerable subjects, such as the elderly.

A typical GC-IMS output response to a breath sample (control subject from this study), is shown in Figure 1. The obtained sample is represented in a 3D topographic map, whereby each point is characterised by the retention time in the chromatographic column (in seconds), the drift time (in milliseconds) and the intensity of ion current signal (in volts). The signal intensity is indicated by colour, where each high-intensity area represents a single or combination of chemjcals (with the same properties). The long line red line is the reactant ion peak (RIP), which is a background signal present all the time. Laboratory Analytical Viewer (LAV) software (v2.2.1, G.A.S., Dortmund, Germany) was used for GC-IMS signal viewing. 


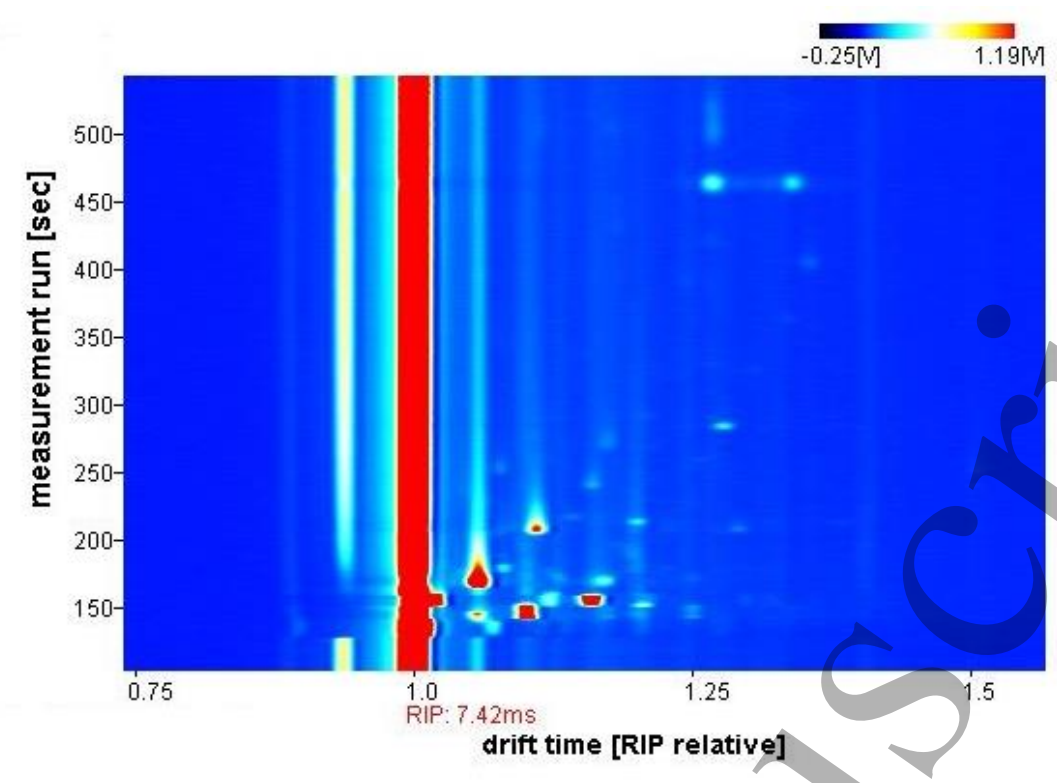

Figure 1. GC-IMS output example.

\subsection{Data analysis}

Our data analysis approach focuses on distinguishing between the three diagnostic groups: $\mathrm{AD}, \mathrm{MCl}$ and controls. However, since there are more controls than $\mathrm{MCI}$ or $\mathrm{AD}$ subjects, the effect of imbalanced datasets needs to be considered [28]. For this reason, a random selection of 25 controls were used for this analysis. The first step of data analysis involves a pre-processing stage. The aim of this is to reduce the dimensionality, thus leaving data that is non-background. A typical GC-IMS dataset contains 11 million data points, which has high dimensionality, but low information content. The area of interest is defined as a region on the GC-IMS output associated with the VOC 'fingerprint' of a subject, i.e. the VOC peak signals. These signals are located near each other in the output file and thus we are able to crop this section of the data. The size of the cropped area is selected by visualisation of the data and ensuring that it can be applied across all samples, without losing any 
Journal of Breath Research

Page | 12

chemical information. The next step involves thresholding. Since we are only interested in the VOC peaks, the spaces between the peaks (i.e. background) is removed using a static threshold. These steps reduce the number of data points by a factor of 100 . Following this, a supervised feature selection procedure is undertaken, with class prediction performed using a $k$-fold cross-validation method (where $\mathrm{k}=10$ in our case). This method/involves partitioning the original data set into 10 equally sized subsets. Of the 10 subsets, a single subset is retained as the validation data for testing the model and remaining nine subsets are used as training data. Training features are identified using Wilcoxon rank-sum test between the two groups and those feature points with the lowest $p$-value selected and used to construct models based on five different classifiers. These features are identified purely on a statistical basis and not on any biological function at this stage. This analysis was run using $R$ (version 3.6.0) with standard machine learning sub-packages: support vector machine (SVM) - kernlab; sparse logistic regression (SLR) - glmnet; Gaussian process - gbm, neural network neuralnet, and random forest (RF) - randomForest. This process is repeated 10 times (number of folds), with each subset used once as validation data. The 10 results are then combined to produce a single estimation and from this, statistical parameters calculated.

In addition to the classification analysis, it is possible to identify unknown VOCs that relate significantly to the efficacy of the generated results. Using GC-IMS Library Search software (v1.0.1, G.A.S., Dortmund, Germany), we can potentially identify compounds based on gas chromatographic retention times and ion mobility drift times, by referencing a NIST database with around 
Journal of Breath Research

83,000 compound entries [29]. Here, we can plot the identified features back onto the original GC-IMS output and then tentatively identify those chemicals. The instrument was normalised to match the GC-IMS Library Search software with the equipped column using a standard ketone mix (2-butanone, 2-pentanone, 2-hexanone, 2-heptanone, and 2-octanone).

\subsection{Confounding factors}

Applications of exhaled breath analysis for diagnostic and/or monitoring purposes should consider possible confounding factors [30]. These are factors which are known to have some impact on breath content and can thus introduce bias or generate spurious associations. For example, age is a critical confounder in this study, because increased age is the biggest risk factor for AD. In addition to age, smoking habits, gender and alcohol consumption were considered. The impact of these factors can be evaluated by re-running the classification analysis applied to the diagnostic groups, after re-organising the patients and volunteers based on confounding factors. To simplify the analysis and create more evenly-balanced groups, the confounding groups were defined as: Age [ $>75$ vs $<=74$ years], smoking habits [never smokers vs ex/current smokers], gender [male vs female] and alcohol consumption [ $>=11$ vs $<11$ units/week]. While the UK guidelines for regular alcohol consumption state that people should consume no more than 14 units of per week [31], men and women over 65 are generally advised to have no more than 11 units per week [32]. Thus, the latter threshold has been used for our confounding factor analysis. The confounding factor groups are summarised in Table 2. 
Table 2. Summary of confounding factor groups.

\begin{tabular}{|c|c|c|c|c|c|}
\hline \multirow{2}{*}{ Factor } & Groups & MCI & AD & Control & Total \\
\hline \multirow{3}{*}{ Age } & $<=74$ years & 15 & 8 & 34 & 57 \\
\cline { 2 - 6 } & $>75$ years & 10 & 17 & 16 & 43 \\
\hline \multirow{3}{*}{ Smoking } & Ex/current smokers & 16 & 15 & 28 & 59 \\
\cline { 2 - 6 } & Never smokers & 9 & 10 & 22 & 41 \\
\hline \multirow{2}{*}{ Gender } & Male & 15 & 14 & 17 & 46 \\
\cline { 2 - 6 } & Female & 10 & 11 & 33 & 54 \\
\hline \multirow{3}{*}{ Alcohol } & $<11$ units per week & 22 & 14 & 31 & 67 \\
\cline { 2 - 6 } & $>=11$ units per week & 3 & 11 & 19 & 33 \\
\hline
\end{tabular}

\section{Results}

Analysis results are presented in Figure 2 as overlapping receiver operating characteristic (ROC) curves. The corresponding area under curve $(A \cup C)$ is a measure of how well parameters can distinguish between diagnostic groups, i.e. $\mathrm{MCl}, \mathrm{AD}$ and controls. We have also calculated NPV (negative predictive value) and PPV (positive predictive value) for the different comparisons. Analysis results for diagnostic groups were achieved using SLR and are shown in Table 3. 
Journal of Breath Research

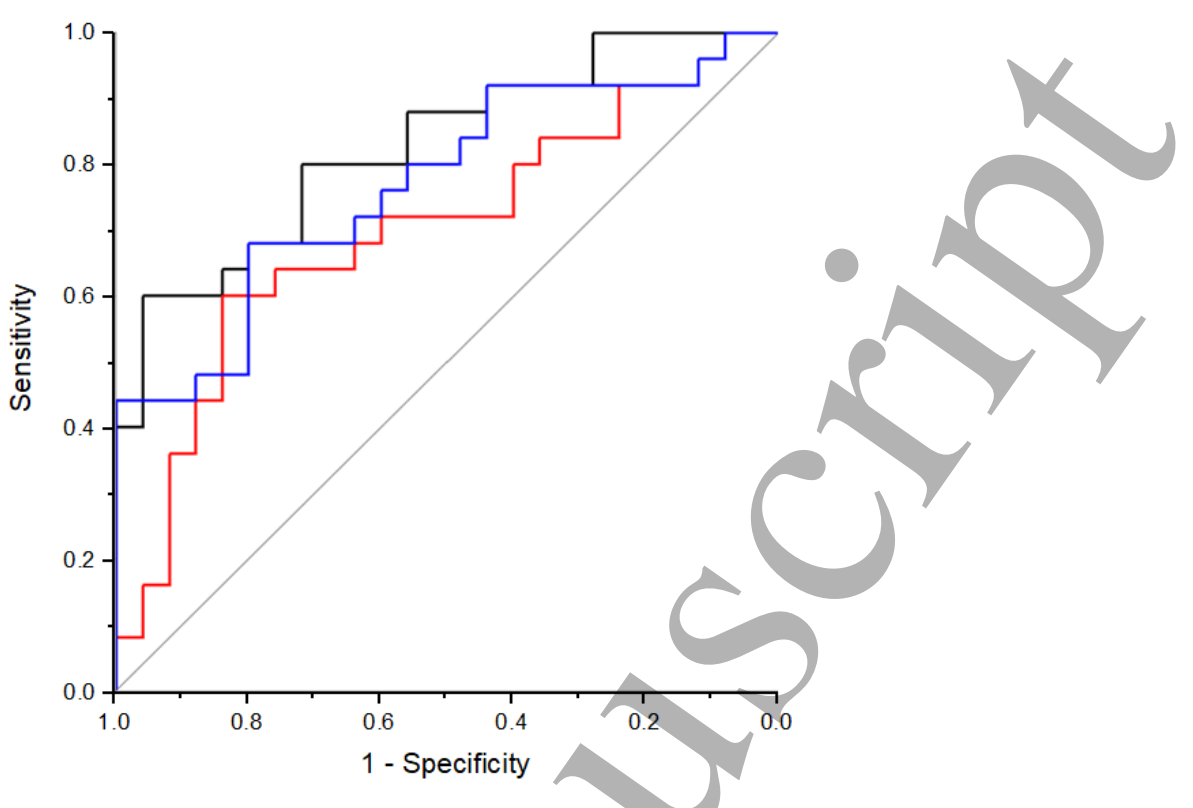

Figure 2. Diagnostic group analysis results: Controls vs $\mathrm{MCl}$ (blue); Controls vs AD (black); MCI vs AD (red). 
Table 3. GC-IMS diagnostic group results.

\begin{tabular}{|c|c|c|c|c|c|c|}
\hline Test & AUC \pm 95\% & Sensitivity & Specificity & PPV & NPV & P-value \\
\hline Controls vs MCI & $0.77(0.64-0.90)$ & $0.68(0.46-0.85)$ & $0.80(0.59-0.93)$ & 0.77 & 0.71 & 0.0004 \\
\hline Controls vs AD & $0.83(0.72-0.94)$ & $0.60(0.39-0.79)$ & $0.96(0.80-1.00)$ & 0.94 & 0.71 & 0.0001 \\
\hline $\mathrm{MCl}$ vs AD & $0.70(0.55-0.85)$ & $0.60(0.39-0.79)$ & $0.84(0.64-0.95)$ & 0.79 & 0.68 & 0.0076 \\
\hline
\end{tabular}


Journal of Breath Research

\subsection{Chemical identification}

VOC analysis indicates that three compounds, tentatively identified as acetone, 2-propanol and 2-butanone play a crucial role in distinguishing between controls and $A D$ subjects. In the test for $A D$ vs $\mathrm{MCl}$, changes in 2-propanol, hexanal and 1-butanol were significant. The separation of controls and $\mathrm{MCI}$ relied on changes observed in 2-propanol, hexanal and heptanal.

\subsection{Confounding factor}

The analysis previously conducted on the $\mathrm{AD}, \mathrm{MCl}$ and control groups was repeated, using the same analytical techniques and algorithms, on the confounding factor groups of age, smoking habits, gender and alcohol consumption. The analysis results are summarized in Table 4. 
Table 4. GC-IMS confounding factors results.

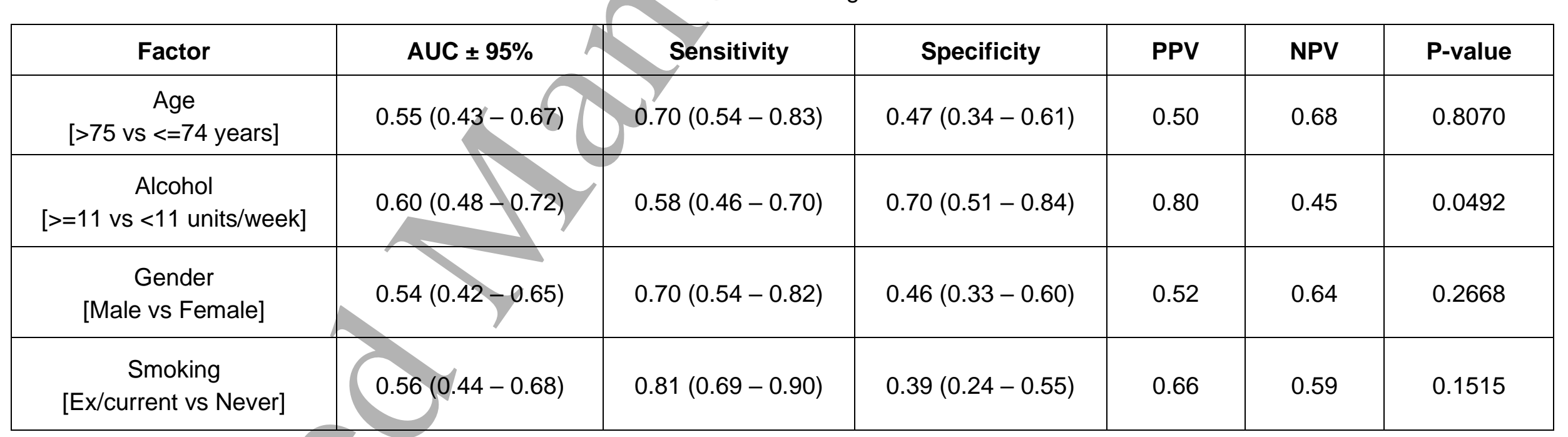


Journal of Breath Research

Page | 19

Table 4 demonstrates that the possible confounding factors of gender, smoking and age have insignificant influence on breath content. Alcohol consumption seems to have the most influence on breath, with an AUC of 0.60 . 
Journal of Breath Research

Page $\mid 20$

\section{Discussion}

While the exact mechanisms related to $A D$ pathogenesis are not fully understood, there is some evidence to suggest that defects in mitochondrial metabolism (i.e. changes in mitochondrial function and potential dysfunction) play a key role in neurodegeneration [33-35]. Furthermore, that mitochondrial dysfunctions in NDDs are associated with increased production of reactive oxygen species (ROS), which cause cell damage and intercellular oxidative stress [36]. Endogenous VOCs (produced in the body) follow metabolic pathways and are transported via the bloodstream to the lungs, where they are exhaled in breath [37]. Oxidative stress has been detected in blood [38] and thus presents an opportunity for the application of breath analysis to facilitate the discovery and evaluation of biomarkers associated with cellular energy metabolism, mitochondrial dysfunction and oxidative stress [7].

In recent years, there have been four original research articles published, investigating the efficacy of breath-based methods for the diagnosis AD [7]. Tisch et al. [18] were the first to test the efficacy of breath testing for the detection of AD and PD. This study included 57 subjects (15 AD, 30 PD, 12 controls) and utilised gas chromatography-mass spectrometry (GC-MS) and nanomaterial-based sensors as analytical platforms. The GC-MS comparison between $A D$ patients and controls yielded 24 substances that occurred in significantly different concentrations and the nanomaterial-based sensor analysis was able to distinguish between $A D$ and controls with a classification accuracy of $85 \%$ (sensitivity $93 \%$, specificity $75 \%$ ). 
Bach et al. [20] used the Cyranose 320 eNose and ion mobility spectrometry (IMS) to detect exhaled breath patterns of AD, PD and controls (18 AD, $16 \mathrm{PD}$ and 19 controls). Results from the eNose were able to somewhat discriminate between groups (sensitivity $76.2 \%$, specificity $45.8 \%$, p-value 0.025). The associated linear discriminant analysis (LDA) model was fitted to a dataset from another site; however, it was not able to detect AD patients (sensitivity $56.6 \%$, specificity 49.1 , p-value 0.658 ). The analysis using IMS detected significant differences in five VOCs and utilised a decision tree of four variables, including 1-butanol and 2-methylfuran, to show an accuracy of $94 \%$ when differentiating patients with AD from controls, i.e. 3 out of 52 AD patients being misclassified. The key disadvantage of using the decision tree approach is that the individual analytes are not suitable to differentiate patients with $A D$ and $P D$ from $H C$; instead, it is a combination and sequence of analytes that make prediction possible.

Lau et al. [19] used a custom-built exhaled breath sensors system and GC-MS to evaluate the breath of 60 subjects (20 AD, 20 PD and 20 controls). GC-MS results showed that four VOCs were consistently present in all patient and control groups. Cluster analysis of the eNose results were able to distinguish between $A D, P D$ and controls.

Mazzatenta et al. [21] used an iAQ-2000 sensor system to investigate the breath of $15 A D$ and 44 controls. The breath frequency of $A D$ patients was increased, compared to the control cohort, but associated with a reduced amplitude. Moreover, the average amount of VOCs in AD patients was less, compared with controls. VOC fingerprint analysis was conducted using clustered VOCs, generated using their relative abundances. These were 
Journal of Breath Research

Page $\mid 22$

observed to differ significantly between exhaled AD breath samples and controls; however, the results were not quantified using AUC, sensitivity, specificity, etc.

Exhaled breath study demographics from previous AD studies (and this study) are summarised in Table 5.

Table 5. Summary of AD-related exhaled breath study demographics.

\begin{tabular}{|c|c|c|c|c|}
\hline \multirow{2}{*}{ Authors } & Groups & $\begin{array}{c}\text { Average age } \mathbf{4} \text { SD } \\
\text { (age range) }\end{array}$ & Male:Female ratio & $\mathbf{N}=$ \\
\hline $\begin{array}{c}\text { Mazzatenta et al. } \\
\text { [21] }\end{array}$ & $\mathrm{AD}$ & $\mathrm{n} / \mathrm{a} \pm \mathrm{n} / \mathrm{a}(55-95)$ & $\mathrm{n} / \mathrm{a}$ & 15 \\
\cline { 2 - 5 } & Controls & $\mathrm{n} / \mathrm{a} \pm \mathrm{n} / \mathrm{a}(19-105)$ & $\mathrm{n} / \mathrm{a}$ & 44 \\
\hline \multirow{3}{*}{ Lau et al. [19] } & $\mathrm{AD}$ & $74.9 \pm 7.5(\mathrm{n} / \mathrm{a})$ & $6: 14$ & 20 \\
\cline { 2 - 5 } & Controls & $67.6 \pm 7.0(\mathrm{n} / \mathrm{a})$ & $5: 15$ & 20 \\
\hline \multirow{3}{*}{ Bach et al. [20] } & $\mathrm{AD}$ & $71.5 \pm 8.7(\mathrm{n} / \mathrm{a})$ & $17: 22$ & 39 \\
\cline { 2 - 5 } & Controls & $63.2 \pm 11.0(\mathrm{n} / \mathrm{a})$ & $16: 19$ & 35 \\
\hline \multirow{3}{*}{ Tisch et al. [18] } & $\mathrm{AD}$ & $68 \pm 10(51-81)$ & $7: 8$ & 15 \\
\cline { 2 - 5 } & Controls & $61 \pm 7(51-73)$ & $5: 7$ & 12 \\
\hline \multirow{3}{*}{ Tiele et al. } & $\mathrm{MCl}$ & $72.2 \pm 7.3(59-86)$ & $15: 10$ & 25 \\
\cline { 2 - 5 } & $\mathrm{AD}$ & $77.5 \pm 7.2(62-90)$ & $14: 11$ & 25 \\
\cline { 2 - 5 } & Controls & $71.2 \pm 7.3(60-87)$ & $17: 33$ & 50 \\
\hline
\end{tabular}

The key advantage of our study is that the ages and genders of the subject cohort are approximately balanced. Furthermore, by recruiting $\mathrm{MCl}$ and $\mathrm{AD}$ patients with their respective partners as controls, it is possible to design a more robust experiment and minimise the possible effects of lifestyle and environmental factors, which can potentially introduce significant interpersonal differences [30]. Moreover, age-matching is a critical factor to consider, since more women than men have $A D$ and other forms of dementia [2]. For example, almost two-thirds of Americans with Alzheimer's are women [39]. It 
Journal of Breath Research

Page | 23

has been suggested that this discrepancy is due to women generally living longer than men, which increases the risk factor of developing AD [40]. However, there are other factors, such as sex-specific genetic and hormonal factors, which can contribute to variance in clinical efficacy [41]. Moreover, lifestyle choices such as smoking, excessive alcohol consumption, poor diet and resulting health conditions (obesity, type-2 diabetes, and cardiovascular disease) can have varied impacts on dementia risk, depending on sex [42]. For this analysis, age was subdivided into 'young elderly' (aged 65-74) and 'older elderly' (aged 75 years or older) [43]. This division accounts for the sharp rise in dementia cases over the age of 75 [5] $-15 \%$ of those with Alzheimer's are aged 65-75, while 44\% are aged 75-85 [2].

VOC analysis indicates that acetone, 2-propanol and 2-butanone contributed significantly to the efficacy of our analysis for AD vs controls. These compounds are generally associated with normal breath [44]. Similarly, changes in other common breath/markers, such as 2-propanol, hexanal, heptanal and 1-butanol, contributed to separation in $A D$ vs $\mathrm{MCl}$ and $\mathrm{MCl}$ vs control tests. This suggests that AD-related changes in breath have a subtle impact on overall breath content. Changes in acetone are of particular interest. Early stages of $A D$ are associated with region-specific declines in brain glucose metabolism [45]. This can be supplemented by ketone bodies, including acetoacetate, $\beta$-hydroxybutyrate and acetone. These are usually produced from fat stores when glucose is unavailable, e.g. during prolonged fasting or when subscribing to a ketogenic diet, which could lead to increased levels of acetone in the exhaled breath in AD patients. AD patients often suffer loss of appetite, with nearly half of mild-AD subjects reporting appetite 
Journal of Breath Research

Page | 24

changes [46]. The changes observed in exhaled acetone in this study could be related to this phenomenon. To the best of our knowledge, there is currently no known link between 1-butanol and metabolic pathways relating to $A D$ or other NDDs. However, concurrence in the identification of this VOC in this study and Bach et al. [20] suggests that there may be a connection, which is worthy of further investigating.

Analysis of possible confounding factors indicate that gender, smoking, age and alcohol consumption have insignificant influence on breath content, in this study. Of these factors, alcohol seems to have the most influence, with an AUC of around 0.60 . However, this factor is not significant enough to create two distinct groups or undermine the AD-related analysis.

A limitation of this study is that the possible effects of medications and co-diseases/conditions were not considered in the confounding factor analysis. However, it should be noted that medication is inherently difficult to adequately assess, since it is not hecessarily possible to discern between pharmacokinetic effects and underlying disease. Moreover, in this case, there are a large number of factors to consider; 65 co-diseases and 73 medications for $\mathrm{MCl}$ subjects and 57 co-diseases and 55 medications reported in the $\mathrm{AD}$ cohort - many of which are age-related instead of disease-related. The possible/effects caused by the most frequently listed co-diseases/conditions and medications are therefore likely to be reduced, as they are similarly represented in both $\mathrm{MCl}$ and $\mathrm{AD}$ groups. Another drawback is that the medication and co-diseases/conditions of controls are not available; however, this group is likely to be associated with similar age-related medication and co-diseases/conditions as the $\mathrm{MCl}$ and $\mathrm{AD}$ groups. 
Journal of Breath Research

While there is a general consensus on clinical diagnostic criteria for patients with $A D$ and $M C l$ due to $A D$, correct clinical diagnosis of $A D$ is reported to be around $77 \%$ [47] - especially since other forms of dementia may be misdiagnosed as $A D$, and vice versa [48]. Misdiagnosis hinders research efforts and clinical trials since incorrect patient groups can obfuscate important findings. However, the results from this study suggest that the patient assessments by Author S.P. were fairly accurate with regard to clinical diagnosis of recruited subjects. Further work from this study should involve recruiting a larger sample size to validate results, reduce the potential effects of incorrect patient groups, and enhance the performance of the applied method (e.g. to increase sensitivity and specificity). In future, we also hope to go beyond distinguishing between diagnostic groups by developing an approach which could be used for personalised disease detection. 
Journal of Breath Research

Page | 26

\section{Conclusions}

Results from this pilot study confirm the potential utility of analysing breath VOCs to distinguish between $\mathrm{MCI}, \mathrm{AD}$ and controls. Though this was a simple study, with relatively clean/well defined groups, our approach was consistently able to separate between diagnostic groups [AUC $\pm 95 \%$, sensitivity, specificity], controls vs MCI: [0.77 (0.64 - 0.9), 0.68, 0.8], controls vs AD: [0.83 $(0.72-0.94), 0.6,0.96]$, and $\mathrm{MCl}$ vs $\mathrm{AD}:[0.70(0.55-0.85), 0.6,0.84]$. Analysis of possible confounding factors suggest that gender, age, smoking habits and alcohol consumption had insignificant influence on breath content. VOC analysis indicates that six compounds, tentatively identified as acetone, 2-propanol, 2-butanone, hexanal, heptanal and 1-butanol play a crucial role in distinguishing between diagnostic groups. The GC-IMS analysis technique was shown to be suitable for non-invasive sampling of elderly subjects and demonstrates potential as a fast, high-throughput, real-time diagnostic tool for $A D$ in a point-of-care clinical setting. 
Journal of Breath Research

Acknowledgments: We would like to thank our subjects at Re:Cognition Health for participating in this study.

Funding: This project was financially supported by Alzheimer's BRACE (UK).

The PhD of A.W. is supported by Lembaga Pengelola Dana Pendidikan (LPDP), Ministry of Finance, Republic of Indonesia.

Conflicts of Interest: The authors declare no conflict of interest 
Journal of Breath Research

\section{References}

[1] Wilson R S, Segawa E, Boyle P A, Anagnos S E, Hizel L P and Bennett D A 2012 The natural history of cognitive decline in Alzheimer's disease. Psychol. Aging 27 1008-17

[2] Alzheimer's Association 2016 Alzheimer's disease facts and fígures Alzheimer's Dement. 12 459-509

[3] Alzheimer's Research UK 2019 Global Prevalence Dement. Stat. Hub

[4] Alzheimer's Disease International 2018 World Alzheimer Report 2018 (London)

[5] Langa K M 2015 Is the risk of Alzheimer's disease and dementia declining? Alzheimers. Res. Ther. 734

[6] Petersen R 2004 Mild cognitive impairment as a diagnostic entity $\mathrm{J}$. Intern. Med. 256 183-94

[7] Subramaniam NS, Bawden C S, Waldvogel H, Faull R M L, Howarth G S and Snell R G 2018 Emergence of breath testing as a new non-invasive diagnostic modality for neurodegenerative diseases Brain Res. $169175-86$

[8] Popp J, Wolfsgruber S, Heuser I, Peters O, Hüll M, Schröder J, Möller H-J, Lewczuk P, Schneider A, Jahn H, Luckhaus C, Perneczky R, Frölich L, Wagner M, Maier W, Wiltfang J, Kornhuber J and Jessen F 2015 Cerebrospinal fluid cortisol and clinical disease progression in $\mathrm{MCl}$ 
and dementia of Alzheimer's type Neurobiol. Aging 36 601-7

[9] de Wilde A, van der Flier W M, Pelkmans W, Bouwman F, Verwer J, Groot C, van Buchem M M, Zwan M, Ossenkoppele R, Yaqub M, Kunneman M, Smets E M A, Barkhof F, Lammertsma A A, Stephens A, van Lier E, Biessels G J, van Berckel B N and Scheltens P 2018 Association of Amyloid Positron Emission Tomography With Changes in Diagnosis and Patient Treatment in an Unselected Memory Clinic Cohort: The ABIDE Project JAMA Neurol. 75 1062-70

[10] Reiman E M, Quiroz Y T, Fleisher A S, Chen K, Velez-Pardo C, Jimenez-Del-Rio M, Fagan A M, Shah A R, Alvarez S, Arbelaez A, Giraldo M, Acosta-Baena N, Sperling R A, Dickerson B, Stern C E, Tirado V, Munoz C, Reiman R A, Huentelman M J, Alexander G E, Langbaum J B S, Kosik K S, Tariot P N and Lopera F 2012 Brain imaging and fluid biomarker analysis in young adults at genetic risk for autosomal dominant Alzheimer's disease in the presenilin 1 E280A kindred: a case-control study Lancet Neurol. 11 1048-56

[11] Nakamura A, Kaneko N, Villemagne V L, Kato T, Doecke J, Doré V, Fowler C, Li Q-X, Martins R, Rowe C, Tomita T, Matsuzaki K, Ishii K, Ishii K, Arahata Y, Iwamoto S, Ito K, Tanaka K, Masters C L and Yanagisawa K 2018 High performance plasma amyloid- $\beta$ biomarkers for Alzheimer's disease Nature 554 249-54 
[12] Besa V, Teschler H, Kurth I, Khan A M, Zarogoulidis P, Baumbach I, Sommerwerck U, Freitag L and Darwiche K 2015 Exhaled volatile organic compounds discriminate patients with chronic obstructive pulmonary disease from healthy subjects Int. J. Chron. Obstruct. Pulmon. Dis. 10 399-406

[13] Altomare D F, Di Lena M, Porcelli F, Trizio L, Travaglio E, Tutino M, Dragonieri S, Memeo V and de Gennaro G 2012 Exhaled volatile organic compounds identify patients with colorectal cancer Br. J. Surg. $100144-50$

[14] Alkhouri N, Singh T, Alsabbagh E, Guirguis J, Chami T, Hanouneh I, Grove D, Lopez R and Dweik R 2015 Isoprene in the Exhaled Breath is a Novel Biomarker for Advanced Fibrosis in Patients with Chronic Liver Disease: A Pilot Study Clin. Transl. Gastroenterol. 6 1-7

[15] Xu M, Tang Z, Duan Y and Liu Y 2016 GC-Based Techniques for Breath Analysis: Current Status, Challenges, and Prospects Crit. Rev. Anal. Chem. 46 291-304

[16] Stüwe S H, Goetze O, Arning L, Banasch M, Schmidt W E, Schöls L and Saft C 2011 Hepatic mitochondrial dysfunction in Friedreich Ataxia BMC Neurol. 11145

[17] Stüwe S H, Goetze O, Lukas C, Klotz P, Hoffmann R, Banasch M, Orth M, Schmidt W E, Gold R and Saft C 2013 Hepatic mitochondrial 
dysfunction in manifest and premanifest Huntington disease Neurology $80743-6$

[18] Tisch U, Schlesinger I, lonescu R, Nassar M, Axelrod N, Robertman D, Tessler Y, Azar F, Marmur A, Aharon-Peretz J and Haick H 2012 Detection of Alzheimer's and Parkinson's disease from exhaled breath using nanomaterial-based sensors Nanomedicine 8 43-56

[19] Lau H-C, Yu J-B, Lee H-W, Huh J-S and Lim J-O 2017 Investigation of Exhaled Breath Samples from Patients with Alzheimer's Disease Using Gas Chromatography-Mass Spectrometry and an Exhaled Breath Sensor System Sensors 171783

[20] Bach J-P, Gold M, Mengel D, Hattesohl A, Lubbe D, Schmid S, Tackenberg B, Rieke J, Maddula S, Baumbach J I, Nell C, Boeselt T, Michelis J, Alferink J, Heneka M, Oertel W, Jessen F, Janciauskiene S, Vogelmeier C, Dodel R and Koczulla A R 2015 Measuring Compounds in Exhaled Air to Detect Alzheimer's Disease and Parkinson's Disease ed D Blum PLOS One 10 e0132227

[21] Mazzatenta A, Pokorski M, Sartucci F, Domenici L and Di Giulio C 2015 Volatile organic compounds (VOCs) fingerprint of Alzheimer's disease Respir. Physiol. Neurobiol. 209 81-4

[22] Hsieh S, McGrory S, Leslie F, Dawson K, Ahmed S, Butler C R, Rowe J B, Mioshi E and Hodges J R 2015 The Mini-Addenbrooke's Cognitive 
Examination: a new assessment tool for dementia Dement. Geriatr. Cogn. Disord. 39 1-11

[23] Borsdorf H and Eiceman G A 2006 Ion Mobility Spectrometry: Principles and Applications Appl. Spectrosc. Rev. 41 323-75

[24] Arasaradnam R P, Covington J A, Harmston C and Nwokolo C U 2014 Review article: next generation diagnostic modalities in gastroenterology - gas phase volatile compound biomarker detection Aliment. Pharmacol. Ther. 39 780-9

[25] Ruzsanyi V, Mochalski P, Schmid A, Wiesenhofer H, Klieber M, Hinterhuber H and Amann A 2012 lon mobility spectrometry for detection of skin volatiles J. Chromatogr. B 911 84-92

[26] Lewis J M, Savage R S, Beeching N J, Beadsworth M B J, Feasey N and CovingtonJ A 2017 Identifying volatile metabolite signatures for the diagnosis of bacterial respiratory tract infection using electronic nose technology: A pilot study PLoS One 12 e0188879

[27] Cao W and Duan Y 2007 Current Status of Methods and Techniques for Breath Analysis Crit. Rev. Anal. Chem. 37 3-13

[28] Saito T and Rehmsmeier M 2015 The Precision-Recall Plot Is More Informative than the ROC Plot When Evaluating Binary Classifiers on Imbalanced Datasets PLoS One 10 e0118432

[29] G.A.S. 2016 GCxIMS Library Search G.A.S. Gesellschaft für Anal. 
Journal of Breath Research

Sensorsysteme

[30] Schooten L B and A S and A B and E T and M S and A Z and J W D and

C W and F J van 2017 Factors that influence the volatile organic

compound content in human breath J. Breath Res. 1116013

[31] GOV.UK 2019 UK Chief Medical Officers' Low Risk Drinking

Guidelines (London)

[32] Royal College of Psychiatrists 2018 Our Invisible Addicts (London)

[33] Hroudová J, Singh N and Fišar Z 2014 Mitochondrial Dysfunctions in

Neurodegenerative Diseases: Relevance to Alzheimer's Disease

Biomed Res. Int. 2014 1-9

[34] Onyango I G, Dennis J and Khan SM 2016 Mitochondrial Dysfunction in Alzheimer's Disease and the Rationale for Bioenergetics Based Therapies Aging Dis. 7 201-14

[35] Perez Ortiz J M and Swerdlow R H 2019 Mitochondrial dysfunction in Alzheimer's disease: Role in pathogenesis and novel therapeutic opportunities Br. J. Pharmacol. 1-19

[36] Andreyev A Y, Kushnareva Y E and Starkov A A 2005 Mitochondrial metabolism of reactive oxygen species. Biochemistry. (Mosc). $70200-$ 14

[37] Wang T, Pysanenko A, Dryahina K, Španěl P and Smith D 2008 Analysis of breath, exhaled via the mouth and nose, and the air in the 
Journal of Breath Research

Page | 34

oral cavity J. Breath Res. 237013

[38] Torres L L, Quaglio N B, de Souza G T, Garcia R T, Dati L M M, Moreira W L, de Melo Loureiro A P, de souza-Talarico J N, Smid J, Porto C S, de

Campos Bottino C M, Nitrini R, de Moraes Barros S B, Camarini R and

Marcourakis T 2011 Peripheral Oxidative Stress Biomarkers in Mild

Cognitive Impairment and Alzheimer's Disease J. Alzheimer's Dis. 26

$59-68$

[39] Hebert L E, Weuve J, Scherr P A and Evans D A 2013 Alzheimer

disease in the United States (2010-2050) estimated using the 2010

census Neurology 80 1778-83

[40] Hebert L E, Scherr P A, McCann J J, Beckett L A and Evans D A 2001 Is the Risk of Developing Alzheimer's Disease Greater for Women than for Men? Am. J. Epidemiol. 153 132-6

[41] Mazure C M and Swendsen J 2016 Sex differences in Alzheimer's disease and other dementias Lancet. Neurol. 15 451-2

[42] Podcasy $\mathrm{J} L$ and Epperson C N 2016 Considering sex and gender in Alzheimer disease and other dementias Dialogues Clin. Neurosci. 18

\section{$437-46$}

[43] Katsura H, Kanemaru A, Yamada K, Motegi T, Wakabayashi R and Kida K 2004 Long-term effectiveness of an inpatient pulmonary rehabilitation program for elderly COPD patients: Comparison between 
Journal of Breath Research

young-elderly and old-elderly groups Respirology 9 230-6

[44] Mochalski P, King J, Klieber M, Unterkofler K, Hinterhuber H, Baumann

M and Amann A 2013 Blood and breath levels of selected volatile organic compounds in healthy volunteers Analyst 138 2134-45

[45] Henderson S T 2008 Ketone bodies as a therapeutic for Alzheimer's disease Neurotherapeutics 5 470-80

[46] Kai K, Hashimoto M, Amano K, Tanaka H, Fukuhara R and Ikeda M 2015 Relationship between eating disturbance and dementia severity in patients with Alzheimer's disease PLoS One10 e0133666

[47] Sabbagh M N, Lue L-F, Fayard D and Shi J 2017 Increasing Precision of Clinical Diagnosis of Alzheimer's Disease Using a Combined Algorithm Incorporating Clinical and Novel Biomarker Data Neurol. Ther. 6 83-95

[48] Qian W, Schweizer T, Munoz D and Fischer C E 2016 Misdiagnosis of Alzheimer's Disease: Inconsistencies Between Clinical and Neuropathological Confirmation Alzheimer's Dement. 12 P293 